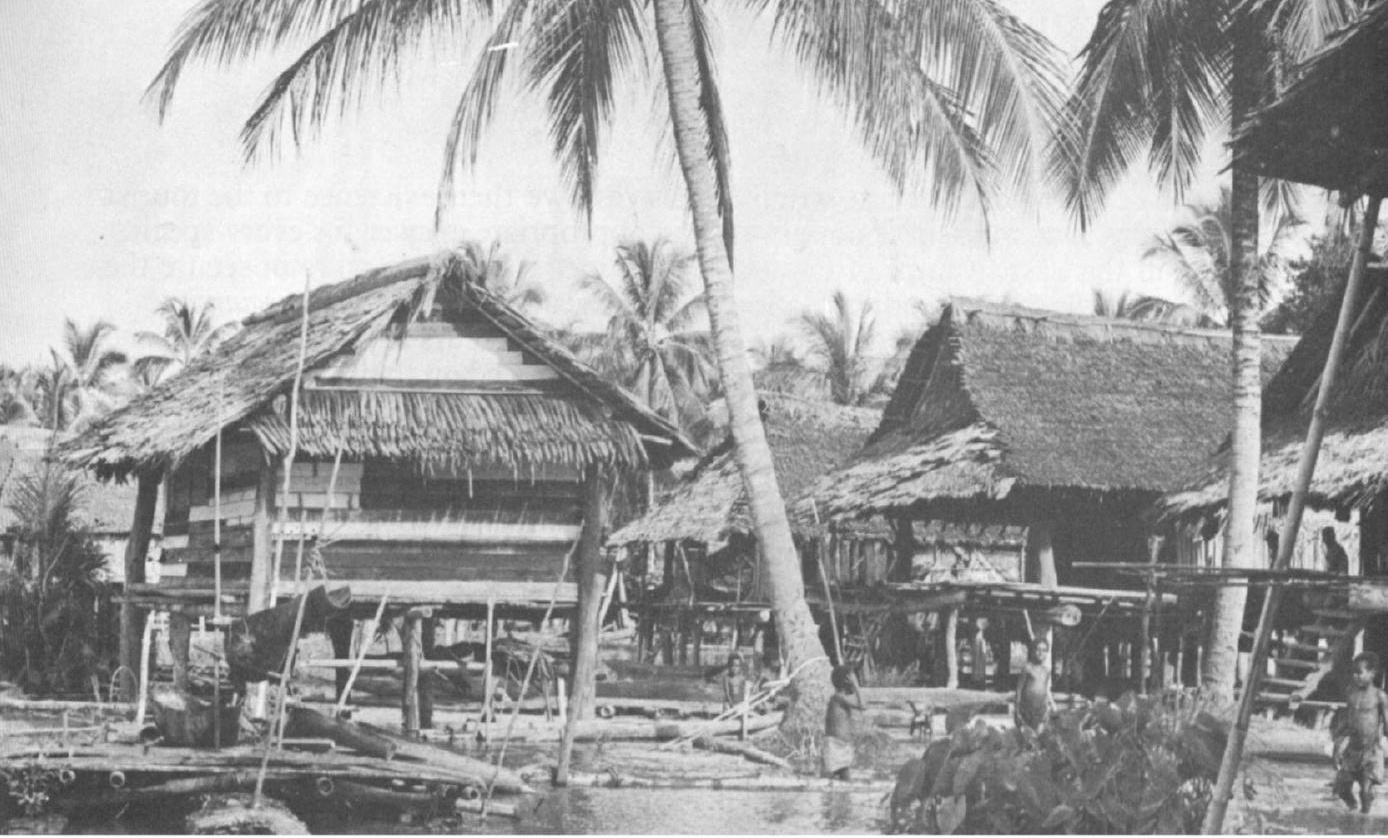

\title{
Crocodile Farming in Papua New Guinea
}

\section{Melvin Bolton}

The swamps and rivers of Papua New Guinea still have large numbers of both freshwater and saltwater crocodiles, and the Government is fully aware of the value of this resource and committed to conserving it. Both crocodile species can be successfully bred in captivity, but an attempt to establish village crocodile farms, where crocodiles would be raised from eggs laid on the farm as distinct from raising captured young wild animals, was not economically attractive to villagers. So farm breeding continues as a research project, while in the villages the aim is to achieve wise utilisation and conservation of the wild stocks.

Saddening though it is, it must be accepted that for many wild animal species, outside parks and reserves, displacement by mankind is inevitable. For them conservation usually has to be directed to securing land where they can be permitted to exist. Even then, their future may not be assured unless the land set aside can pay its way in competition with other forms of land use. Thus, 
some of the world's finest wildlife reserves owe their existence to the tourist industry. But tourism is not always the appropriate answer for every species, and in the vast swamps of Papua New Guinea it certainly will not secure the future of the two crocodile species: the freshwater Crocodylus novaeguineae and the so-called saltwater crocodile $C$. porosus which occurs in both sea and inland waters. For them an entirely different strategy based on their intrinsic value is being tried.

The Papua New Guinea crocodile populations have been so reduced that they are no longer a serious hazard around human settlements, but away from settlements there are still enough to produce tens of thousands of youngsters every year. The main strongholds are the swamps of the Sepik and Ramu Rivers in the north, and of the Fly River and smaller rivers flowing into the Gulf of Papua to the south. People in these regions are not only very familiar with crocodiles but have incorporated them into their cultural (and culinary) traditions. They also hunt them for the skin trade.

Until the mid-1960s crocodiles and other wildlife resources were heavily exploited virtually without restriction. But in 1966 a wildlife branch was established within the Ministry of Agriculture, Stock and Fisheries, and in 1968 Max Downes was appointed its ecologist. His considerable energy and enthusiasm resulted in legislation to control the destruction of wild crocodiles by prohibiting the export of all skins over $50 \mathrm{~cm}$ (20in) belly width. This corresponds to a length of about two metres (or less) and is the approximate size at which the two species start breeding. The aim was both to conserve the breeding stocks and to harvest an annual supply of youngsters for farm rearing.

The highest natural mortality in wild crocodiles occurs among the very young-most die within the first year or two-so there does indeed appear to be a harvestable surplus. It was therefore planned to take an annual harvest of young animals and rear them in a national network of farms, ranging from small temporary holding pens, built by the hunters, and village and community enterprises to large commercial farms. The wasteful killing of small crocodiles was discouraged by a tariff which made the export of very small skins relatively unprofitable. UNDP/FAO agreed to support the scheme, and on January 1st 1977 a large-scale project entitled 'Assistance to the Crocodile Skin Industry' became operational. Now, eighteen months later, in addition to the small numbers of government-run demonstration and experimental farms, there are

FEEDING TIME 


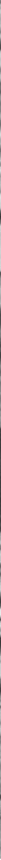

New Guinea freshwater crocodile skin

over 200 small village farms throughout the country; also several larger business groups have been formed, each with a holding of several hundred crocodiles. However, the majority of the small farms are not operating at anywhere near maximum efficiency, due to lack of technical know-how, shortage of funds for basic equipment and the many problems of villagers in remote areas.

The FAO-assisted project is designed to improve and extend the existing network of farms so as to establish an organised industry able to compete with, and ultimately replace, the present hunting of crocodiles for skins. As long as a market for skins exists it is politically and indeed practically impossible to prohibit hunting without providing a profitable alternative for the people. For under Papua New Guinea law the resource belongs to the people in whose territory it exists; they must be given a good reason for safeguarding its future. Crocodile farming would be a singularly appropriate rural industry for these isolated lowland communities whose land is not suitable for most forms of agriculture and who are therefore vulnerable to rural-urban drift. A successful farming scheme would also increase the country's foreign exchange earnings and establish crocodiles as a significant regional and national asset with a future.

The farms are nearly all stocked with small wild hatchlings captured in the swamps. These are kept in pens, usually with fences built from local unseasoned wood, and fed each day on fish or offal as available. Crocodiles need relatively little food, being normally not very active, and a pen of fifty youngsters would need only about two kg (4.4lb) a day during the first year. But it must be fresh, and the pens must be supplied with water and shade and kept clean. Under these conditions growth rates are good and the crocodiles are ready for slaughter after three years when the belly width is approaching $50 \mathrm{~cm}$. Killing is done most quickly and humanely by severing the spinal cord with a knife just behind the skull, the crocodile having been caught with a noose 
around its jaws and the jaws tied. The skin of the belly, flanks and limbs is removed in one piece-any damage at this stage will lower its grade and valuethe feet and the plated dorsal strip of skin are discarded, and the meat can be fed to the crocodiles, or cooked and eaten by the farmer, or even sold to a hotel. It is already popular with tourists in one motel in the capital, though another, more cautious, hotelier on the north coast had it on his menu as 'white steak $a$ la Melvin'!

Preservation of the skin is vitally important and it must be scraped and treated with salt and preservatives before being rolled for storage and transport. The owner may export it if he has an export licence, or sell it to an exporter as appropriate, but most small farmers are encouraged to grow crocodiles on for a season or so and then sell them to a bigger holding, which is better placed for dealing with the animals in their final year. The aim is to be able to show a profit at each stage without any crocodiles being wasted by premature slaughter or inadequate skinning and preservation.

Obviously everything depends on a continuing supply of wild hatchlings, and high priority must be given to monitoring the effects of harvesting on the wild population in order to determine whether it can, as is believed, sustain the industry at the present or higher cropping levels. The legislation has a provision for setting aside wildlife management areas in which the capture or disturbance of crocodiles could be restricted or prohibited if need be. Such measures can only be successful if supported by the local people, but there is reason to believe that such support would be forthcoming where the need could be shown. At present, although the vast swamps appear to be yielding an adequate supply of young crocodiles, there are some regional scarcities, and there are already local plans for two wildlife management areas on the Sepik. It is to be hoped that they materialise.

In the long term breeding crocodiles in captivity is a feasible proposition; both species have bred successfully in the government's main demonstration farm near Port Moresby. But it requires care and space, and it is not economically attractive to villagers with wild hatchlings virtually on the doorstep. The freshwater crocodile is not sexually mature until it is eight to ten years old and the saltwater species probably not until considerably more, even though both can be expected to produce upwards of 30 eggs a year. So for the time being, at the village farming level, the project will concentrate on conservation in the sense of 'wise utilisation' of the wild stocks. Captive breeding will continue as a research programme only.

Another possibility is to collect eggs instead of hatchlings. The number of eggs lost in the wild, especially from flooding, could be enormous in some years. Egg collection and farm incubation would seem to be the obvious method of precluding this early mortality. But there is a danger in encouraging villagers to collect eggs before they have the necessary knowledge and expertise; embryos can be killed merely by careless handling. So for the immediate future egg collection will also be restricted to a pilot scheme.

Research is also being organised to test different feeding and husbandry techniques and investigations into several aspects of crocodile biology are continuing. Market research will not, of course, be ignored but the project does not include skin processing beyond the preparation of raw skins for export. Top grade, good quality skins find a ready market in the east and also in the west, where leading tanneries in the USA and France carry out the final processing. 
The finished, high quality leather is then dyed to fashionable colours and made up into durable, if expensive, goods for sale. The demand for skins shows no signs of falling off, and the world supply continues to diminish as crocodiles are exterminated both by deliberate hunting and by the mere pressure of expanding human populations. So the market prospects for Papua New Guinea are good, especially as C.porosus produces the most valuable skin of all. Indeed skin prices for both species have increased so much recently that constant vigilance and adjustment of tariffs and live crocodile prices will be needed to support the long-term interest of farming against the more short-sighted desires of those who would make hay while the sun shines.

If the farming scheme can be made to work, Papua New Guinea could become almost unique in being able to produce crocodile skins in commercial quantities without depleting wild stocks and threatening the continued existence of the species. The government is well aware of this and is committed, with UN help, to the task of developing a lucrative industry while conserving the fundamentally more valuable wildlife resource.

Editor's Note: The Papua New Guinea crocodile-breeding scheme is sound conservation for the crocodiles of that country, but will success be achieved at the expense of the rest of the world's crocodiles? PNG has not destroyed its crocodiles, and so can build up a valuable trade on a sustained yield basis. But every other crocodile species in the world is endangered, and an international trade in crocodile skins, such as the PNG scheme will encourage, makes it all the easier for poachers to smuggle out skins of the endangered species in Africa and South America to add to the supply. This is exactly the problem that is faced in conserving the marine turtles, for which farming (if it can be achieved) seems the sensible solution, but to create a world demand is to encourage the poachers to supply it. At least with turtles, which are wanted for meat, it is possible to restrict farms to supplying only local markets and forbid all exports. With crocodiles this is not possible. It should be possible to ensure that none but legally exportable crocodile skins are imported by other countries, but experience has shown that in practice this is difficult to achieve. Nevertheless, it is clearly what has to be done.

\section{Nature Reserve in a Capital City}

In Kandy, capital of the hill country of Sri Lanka, there survives a 250 acre forest, relic of a former 1000-acre nature reserve called Udawattekalli (the forest on the hill). Despite illegal tree felling and a depleted fauna and flora, jackals, porcupines and mouse deer survive, and bird life is abundant, with 80 species including sharma, yellow-braved bulbul, Indian blue chat and Ceylon grackle. As a result of an appeal to the Government by the Wildlife and Nature Protection Society of Ceylon, the 250 acres have now been fenced as a nature reserve, the first urban nature reserve in Sri Lanka. The University is compiling a list of indigenous trees and shrubs for replanting, ponds are being cleaned and silt removed to facilitate fish breeding, and nature trails laid out. The resulting mixture of woods, open parkland and lakes will provide good study areas for students. No vehicles will be allowed and the whole place will be guarded. The cost estimated at Rs 110,000 ( $£ 6200)$ will be met by the Government.

\section{Using Dogs to Save Black-footed Ferrets}

The New Mexico Department of Game and Fish will soon be using dogs to sniff out the rare black-footed ferrets Mustela nigripes in prairie dog colonies earmarked for poisoning. The ferrets prey on prairie dogs and live in their colonies, and were nearly exterminated when the practice of poisoning the prairie dogs became widespread. None has been seen in New Mexico in recent years, but the Game and Fish Department hopes that the dogs will be able to find some, which would then be relocated. 